\title{
Long-term preservation of freeze-dried rabbit sperm by adding rosmarinic acid and different chelating agents
}

\author{
Paula Domingo $^{\mathrm{a}, *}$, Maite Olaciregui ${ }^{\mathrm{a}}$, Noelia González ${ }^{\mathrm{a}}$, Ignacio De Blas ${ }^{\mathrm{b}}$, Lydia Gil ${ }^{\mathrm{a}}$ \\ a Department of Animal Pathology, Obstetric and Reproduction Area, Faculty of Veterinary Medicine, Universidad de Zaragoza, Miguel Servet 177, 50013, Zaragoza, Spain \\ b Department of Animal Pathology, Animal Health Area, Faculty of Veterinary Medicine, Universidad de Zaragoza, Miguel Servet 177, 50013, Zaragoza, Spain
}

\section{A R T I C L E I N F O}

\section{Keywords:}

DNA fragmentation

Freeze-drying

Halomax

Rabbit sperm

Rosmarinic acid

\begin{abstract}
A B S T R A C T
Freeze-drying (FD) technique has been applied as an alternative technology to preserve gene resources to allow simple sperm preservation and shipment at $4{ }^{\circ} \mathrm{C}$. Nevertheless, DNA sperm might be damaged by mechanical or oxidative stress throughout FD procedure. Therefore, suitable protection to maintain DNA integrity is required. The aim of this study was to determine the effect of rosmarinic acid (RA) as an antioxidant and two chelating agents (EGTA and EDTA) on the DNA integrity of freeze-dried rabbit sperm after storage of the samples at $4{ }^{\circ} \mathrm{C}$ and room temperature for 8 months. Rabbit sperm were freeze-dried in basic medium $(10 \mathrm{mM}$ Tris- $\mathrm{HCl}$ buffer and $50 \mathrm{mM} \mathrm{NaCl}$ ) supplemented with $50 \mathrm{mM}$ EGTA (1), $50 \mathrm{mM}$ EGTA plus $105 \mu \mathrm{M}$ RA (2), $50 \mathrm{mM}$ EDTA (3) or $50 \mathrm{mM}$ EDTA plus $105 \mu \mathrm{M}$ RA (4). Semen samples were kept at $4{ }^{\circ} \mathrm{C}$ and room temperature during 8 months. After rehydration, DNA integrity was evaluated with Sperm Chromatin Dispersion test observing that DNA fragmentation was higher when semen samples were freeze-dried with EGTA (10.9\%) than with EDTA (4.1\%) $(p<0.01)$. Furthermore, RA acted better under adverse conditions and no significant differences were found in temperature storage. Summarizing, FD is a method that can allow simple gene resources preservation among $4{ }^{\circ} \mathrm{C}$ to $25^{\circ} \mathrm{C}$ during 8 months and transportation without the need for liquid nitrogen or dry ice. EDTA chelating agent is the most suitable media for freeze-dried rabbit sperm and the addition of RA protects the DNA against the oxidative stress caused during FD procedure.
\end{abstract}

\section{Introduction}

Assisted Reproductive Technologies in mammals has been steadily progressing. Freeze-drying (FD) procedure, or lyophilisation, has been applied as an alternative technology to preserve gene resources [7-11,13,24]. The feasibility of this method is owing to the evidence that freeze-dried spermatozoa allows viable offspring by intracytoplasmic sperm injection (ICSI) in rabbits [15], mice $[5,7,13,14,24,25]$, rats [3,4] and horses [1]. In addition, FD technology allows simple sperm preservation and shipment at $4{ }^{\circ} \mathrm{C}$ without noticeable deterioration, meaning that neither liquid nitrogen nor dry ice is required [4,7]. Room temperature would be ideal for long-term freeze-dried sperm storage and shipment.

Nevertheless, sperm DNA might be damaged by mechanical or oxidative stress throughout FD procedure [13,14]. It is suggested that $\mathrm{Ca}^{2+}$ and $\mathrm{Mg}^{2+}$ divalent cations activate sperm endogenous nucleases from plasma membrane during FD procedure causing DNA sperm damage and chromosome aberrations [13,21]. Previous studies in mice have reported that chelating agents such as ethylene glycol-bis(2-

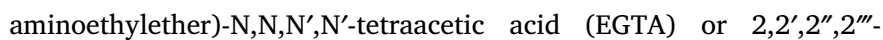
(ethane-1,2-diyldinitrilo)tetraacetic acid (EDTA) added to freeze-drying medium can be combined with divalent cations forming stable complexes and thus protect DNA sperm from degradation [5,13,14]. Additionally, oxidative stress and reactive oxygen species (ROS) were previously associated with DNA sperm degeneration [13,14]. Rosmarinic acid (RA) is a natural antioxidant [20] that has shown therapeutic effects against oxidative stress in in vitro cell studies [12]. It has been demonstrated that the incorporation of RA in freezing $[16,26]$ and FD [18] medium provides protection on spermatozoa against oxidative stress and thus improves the quality of sperm preservation.

To our knowledge, no studies have been performed to evaluate the effect of antioxidants on freeze-dried rabbit sperm.

The aim of this study was to determine the effect of RA as an antioxidant and two chelating agents (EGTA and EDTA) on the DNA integrity of freeze-dried rabbit sperm after storage at $4{ }^{\circ} \mathrm{C}$ and room temperature for 8 months. In addition, the influence of the storage temperature also was evaluated.

\footnotetext{
* Corresponding author.

E-mail address: paula.domingo.tomas@gmail.com (P. Domingo).
} 


\section{Materials and methods}

\subsection{Reagents and media}

Unless noted otherwise, all chemicals were from Sigma-Aldrich Co. (Alcobendas, Madrid, Spain). Freeze-drying control media used were: EGTA and EDTA. EGTA medium was composed of basic medium (10 mM Tris-HCL buffer and $50 \mathrm{mM} \mathrm{NaCl}$ ) supplemented with $50 \mathrm{mM}$ EGTA and EDTA medium was composed of basic medium (10 mM TrisHCL buffer and $50 \mathrm{mM} \mathrm{NaCl}$ ) supplemented with $50 \mathrm{mM}$ EDTA. Two more experimental FD media were prepared by adding $105 \mu \mathrm{M}$ RA to EGTA (EGTA-RA) and EDTA (EDTA-RA) [16]. The final pH of the solutions were adjusted to between 8.2 and 8.5 [9].

\subsection{Animals}

The study was performed following approval by the Veterinary Ethical Committee of University of Zaragoza. The care and use of animals were performed according to the Spanish Policy for Animal Protection RD1201/05, which meets the European Union Directive 86/ 609 on the protection of animals used for experimental and other scientific purposes.

All semen samples were collected from eight sexually mature bucks previously selected from at a commercial AI centre (Técnicas Cunícolas S.A.). Males were maintained in individual cages under light cycle of $12 \mathrm{~h}$ light/dark at a room temperature of $22-24^{\circ} \mathrm{C}$ and a relative humidity of $55-60 \%$. All animals were fed a commercial pellet diet according to their reproductive condition and fresh water was given ad libitum.

\subsection{Collection of rabbit spermatozoa}

Rabbit sperm samples were collected by artificial vagina. After semen collection, any gel plug was removed. Immediately a macroscopic analysis was performed to assess the colour and the volume of each ejaculate and the motility was evaluated by integrated sperm analysis system (ISAS ${ }^{\circ}$; PROISER R + D, Valencia, Spain). Only ejaculates with white colour, $>0.2 \mathrm{~mL}$ and good wave motion (at least $85 \%$ of motility) were used for the research. Thereafter all ejaculates were pooled, in order to eliminate individual differences, and diluted in pre-warmed $\left(37^{\circ} \mathrm{C}\right.$ ) INRA $96^{\circ}$ (IMV Technologies, L'Aigle, France).

\subsection{Freeze-drying and rehydration procedures}

Freeze-drying procedure was performed as reported by Wakayama and Yanagimachi (1998) [24]. Heterospermic solution was divided into four falcon tubes for centrifuge at $700 \mathrm{~g}$ for $10 \mathrm{~min}$ at $37^{\circ} \mathrm{C}$ and the supernatant was discarded. Afterwards, each falcon tube was resuspended in four FD media, EGTA, EGTA-RA, EDTA and EDTA-RA. $150 \mu \mathrm{L}$ of sperm suspension from each group were placed into $1 \mathrm{~mL}$ volume glass cryovials (Labcon North, America, USA) and then plunged into liquid nitrogen $\left(\mathrm{LN}_{2}\right)$ for $5 \mathrm{~min}$. Immediately the frozen samples were transferred onto the shelf $\left(-50{ }^{\circ} \mathrm{C}\right)$ of a programmable freezedrier (Lyobeta 25, Telstar). Two drying phases were performed for freeze-dry the samples: a primary drying at $0.053 \mathrm{mbar}$ of pressure and at $-68{ }^{\circ} \mathrm{C}$ and a second drying at $0.018 \mathrm{mbar}$ of pressure and $20^{\circ} \mathrm{C}$ of temperature. After FD process, cryovials were sealed with rubber cups and parafilm. Dried samples were stored in a conventional glass desiccator at $4{ }^{\circ} \mathrm{C}$ and room temperature $\left(25^{\circ} \mathrm{C}\right)$ during 8 months.

The rehydration of freeze-dried spermatozoa was performed by adding $300 \mu \mathrm{L}$ of Milli-Q water. Rehydrated spermatozoa were centrifuged once at $1000 \mathrm{~g}$ during $2 \mathrm{~min}$ and the supernatant was removed. The pellet was resuspended in $500 \mu \mathrm{L}$ phosphate buffered saline (PBS) and thereafter the analysis of DNA integrity was performed by Sperm Chromatin Dispersion (SCD) test (Halotech DNA SL, Madrid, Spain).

\subsection{Sperm DNA fragmentation analysis}

Sperm Chromatin Dispersion test specifically designed for oryctolagus cuniculus spermatozoa (O.cuniculus-Halomax ${ }^{\circ}$ kit) was used to evaluate sperm DNA fragmentation from freeze-dried spermatozoa. Succinctly, following the manufacturer's instructions, $25 \mu \mathrm{L}$ of each diluted sperm sample was gently mixed with $50 \mu \mathrm{L}$ of low melting point agarose. Subsequently, $2 \mu \mathrm{L}$ of the cell suspension was placed onto marked wells and each drop was covered with $24 \times 24 \mathrm{~mm}$ glass coverslip. The slides were kept horizontally at $4{ }^{\circ} \mathrm{C}$ for $5 \mathrm{~min}$ to solidify the agarose. Then coverslips were removed and the slides were fully immersed horizontally in $10 \mathrm{~mL}$ of lysis solution for $5 \mathrm{~min}$. After washing the samples in distilled water for $5 \mathrm{~min}$, the slides were dehydrated through two successive ethanol baths (70\% and 100\%) for $2 \mathrm{~min}$ in each one and air-dried. Finally, the cells were stained using a green fluorescence microscopy staining kit (FluoGreen ${ }^{\circledR}$, Halotech DNA SL, Madrid, Spain). Once reagent A was mixed with reagent B in a 1:1 proportion, $3 \mu \mathrm{L}$ of the mix was placed over the slide and was covered with a coverslip. The slides were checked under fluorescence microscopy (Olympus BX-40, Olympus U-RFL-T, Tokyo, Japan) at magnification $400 \times$ and at least 400 spermatozoa were counted per semen sample.

\subsection{Statistical tests}

The study was replicated three times. Data were analysed using IBM SPSS Statistics 23 for Windows. DNA fragmentation data were expressed in percentages and analysed by chi-squared test. The level of significance was set at $\mathrm{p}<.050$.

\section{Results}

The different halo patterns of sperm DNA fragmentation after FD procedure analysed by SCD test are shown in Fig. 1. Spermatozoa with

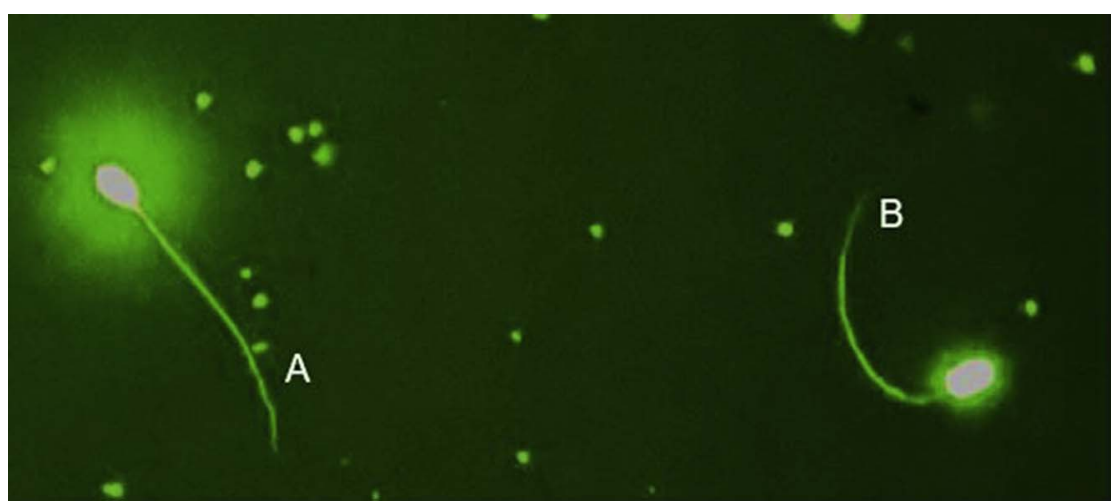

Fig. 1. Freeze-dried rabbit sperm processed with Sperm Chromatin Dispersion test. Fragmented sperm (A) and non-fragmented sperm (B). 
Table 1

Effect of freeze-drying medium, rosmarinic acid and storage temperature on DNA integrity of lyophilize rabbit sperm. Different letters denote statistical differences $(p<.050)$.

\begin{tabular}{lcll}
\hline Freeze-drying medium & Rosmarinic acid & $4{ }^{\circ} \mathrm{C}$ & $25^{\circ} \mathrm{C}$ \\
\hline \multirow{2}{*}{ EDTA } & - & $3.7^{\mathrm{a}}$ & $4.7^{\mathrm{a}}$ \\
& + & $4.1^{\mathrm{a}}$ & $4.2^{\mathrm{a}}$ \\
EGTA & - & $11.1^{\mathrm{bc}}$ & $12.5^{\mathrm{c}}$ \\
& + & $10.6^{\mathrm{bc}}$ & $9.5^{\mathrm{b}}$ \\
\hline
\end{tabular}

fragmented DNA reflected a large and spotty halo of chromatin dispersion unlike non-fragmented DNA spermatozoa which presented a small and compacted halo.

The data obtained after analysed the DNA damaged of freeze-dried rabbit sperm treated in different ways and stored during 8 months at $4{ }^{\circ} \mathrm{C}$ and room temperature are shown in Table 1. Freeze-dried sperm samples treated with EDTA showed a lower percentage of sperm with fragmented DNA (4.1\%) than EGTA sperm samples (10.9\%) $(p<.001)$. In fact, EGTA sperm samples stored at $25^{\circ} \mathrm{C}$ were the most damaged DNA spermatozoa observed, although when RA was added to EGTA freeze-dried medium before FD and stored at $25^{\circ} \mathrm{C}$ the percentage of spermatozoa with intact DNA increased significantly $(p=.019)$. However no significant differences were found in storage EDTA sperm samples at $4^{\circ} \mathrm{C}$ or $25^{\circ} \mathrm{C}$ not even when were supplemented with RA.

\section{Discussion}

Freeze-drying procedure has been applied as an alternative reproductive technology to preserve animal gene resources and increase the biobank genetic diversity $[7,10]$.

Several previous studies have attempted to improve FD method in order to achieve viable animals offspring [1,3-5,7,13-15,24]. Interestingly, some studies demonstrated that $\mathrm{Ca}^{2+}$ and $\mathrm{Mg}^{2+}$ divalent cations were responsible for DNA sperm damage and chromosome aberrations [13,21] and moreover, chelating agents such as EGTA or EDTA added to FD medium can be combined with divalent cations forming stable complexes and thus protect sperm DNA from degradation $[5,13,14]$. The present study has demonstrated for the first time that EDTA chelating agent added to FD medium protect rabbit sperm DNA better than EGTA during FD process. This observation is in agreement with Olaciregui et al. [19] who reported that EDTA and EGTA have different chelating actions although, unlike our results, Olaciregui et al. [19] determined that EGTA is a greater chelating agent than EDTA in freeze-dried dog sperm. Similarly, Nakai et al. [17] reported that EGTA is more suitable than EDTA for adding to FD buffer for boar sperm since EGTA improves in vitro developmental ability of injected oocytes to the blastocyst stage. The only research performed in freeze-dried rabbit sperm used EGTA as FD medium but was not been compared with other chelating agent [15].

In contrast, Kaneko and Nakagata [5] have shown that EDTA prevents sperm DNA degeneration more efficiently and at lower concentrations than EGTA during FD and preservation of mouse spermatozoa. Additionally, Gianaroli et al. [2] demonstrated that the process of FD by using EDTA chelating agent does not affect DNA integrity of human spermatozoa, the proportion of spermatozoa with fragmented DNA in fresh samples $(77.8 \%)$ being similar to samples which were subjected to FD process (80.6\%).

Comparing our findings in freeze-dried rabbit sperm with others in boar, dog, mouse and human sperm, we suggest that even though EDTA and EGTA are both great chelating agents, its effectivity depends on the concentration and the animal species which are used.

To our knowledge, there has not been any report about the influence of antioxidant supplementation on rabbit sperm preservation. As known, FD technique can disrupt the balance between the production of ROS and detoxification. The oxidative stress produced by the excess of
ROS leads to strand breaks, base modification and cross-linking of the DNA [22,23]. Zhang et al. [26] reported that the antioxidants could minimize the detrimental effect of ROS and improve the quality of spermatozoa. Besides, Luño et al. [16] showed that RA antioxidant provides a protection against oxidative stress during boar sperm cryopreservation and likewise, Olaciregui et al. [18] observed that the addition of RA to EGTA FD medium decreases significantly $(p=.003)$ the percentage of DNA damage in freeze-dried ovine spermatozoa. Lastly, Kodama et al. [12] demonstrated that antioxidant treatment in humans with high level of oxidative sperm DNA damage may reduce the extensive oxidative DNA damage. In this study, the addition of RA antioxidant to FD medium reduced the percentage of fragmented freezedried rabbit spermatozoa. To highlight, RA exerted greater protection when samples underwent high degree of oxidative stress. EGTA samples stored at $25^{\circ} \mathrm{C}$ showed the higher percentage of fragmented DNA (12.5\%), despite this the supplementation of RA decreased significantly ( $\mathrm{p}=.019)$ the percentage of fragmented spermatozoa (9.5\%). Under good conditions the effect of RA was not noted. EDTA samples stored at $4{ }^{\circ} \mathrm{C}$ exhibited a lower percentage of fragmented spermatozoa (3.7\%), however the addition of RA increased the DNA damage (4.1\%). On the other hand, EDTA samples stored at $25^{\circ} \mathrm{C}$ showed higher percentage of fragmented DNA (4.7\%) than samples stored at $4{ }^{\circ} \mathrm{C}$ but in this case, the supplementation with RA decreased the percentage of fragmented DNA (4.2\%). These results suggest that the addition of RA to FD medium decrease the damage of DNA when samples undergo high degree of oxidative stress. When EDTA FD medium is used, the balance between the amount of ROS and detoxification is compensated by the chelating agent and RA may interfere in its action. It should be noted that in the study of Olaciregui et al. [18] in freeze-dried ovine spermatozoa, the percentage of fragmented DNA in EGTA (4.4\%) and EGTA-RA (2.9\%) was lower than our results, concluding that RA is more efficient when samples are diluted with EGTA and that DNA of rabbit spermatozoa diluted with EGTA is more sensitive to FD process than the ovine equivalent.

Regardless of no significant differences being found after storage of EDTA or EGTA rabbit sperm samples at $4{ }^{\circ} \mathrm{C}$ or $25^{\circ} \mathrm{C}$, not even when were supplemented with RA, data showed that sperm samples stored at $4^{\circ} \mathrm{C}$ had little less damage to the DNA. Other authors have reported previously, in other animals such as mouse [6,24], rats [4] and dogs [19], that the most suitable temperature to keep freeze-dried sperm is $4{ }^{\circ} \mathrm{C}$. In this way, FD method offers many advantages over cryopreservation at $-196{ }^{\circ} \mathrm{C}$ where a constant supply of liquid nitrogen is required. This study is a breakthrough because it shows that it is possible to preserve gene resource during 8 months at room temperature making the transport of the samples over the world easier and cheaper.

Finally it is interesting to highlight that to date, there has not been any report about the influence of antioxidant supplementation on freeze-dried rabbit spermatozoa. Therefore, freeze-drying is a method that can allow simple gene resources preservation among $4{ }^{\circ} \mathrm{C}$ to $25^{\circ} \mathrm{C}$ and transportation without the need for liquid nitrogen or dry ice. Unlike other animals [17-19], EDTA chelating agent is the most suitable media for FD rabbit sperm under the conditions employed here and the addition of RA can protect the DNA against the oxidative stress caused during FD procedure.

\section{Authors' contributions}

All authors are aware of the submission and agree to be listed as coauthors. All authors have read and approved the final version of the manuscript.

\section{Competing interests}

None of the authors declare competing financial interests. 


\section{ACKNOWLEDGEMENTS}

The authors wish to thank Miguel Domingo, chief of Técnicas Cunicolas S.A. farm, for the assistance in the fieldwork. This study was supported by Government of Aragon Research Groups (Fondo Social Europeo, DGA) and IA2.

\section{References}

[1] Y.H. Choi, D.D. Varner, C.C. Love, D.L. Hartman, K. Hinrichs, Production of live foals via intracytoplasmic injection of lyophilized sperm and sperm extract in the 321 horse, Reproduction 142 (2011) 529-538.

[2] L. Gianaroli, M.C. Magli, I. Stanghellini, A. Crippa, A.M. Crivello, et al., DNA integrity is maintained after freeze-drying of human spermatozoa, Fertil. Steril. 97 (5) (2012) 1067-1073.

[3] M. Hirabayashi, M. Kato, J. Ito, S. Hochi, Viable rat offspring derived from oocytes intracytoplasmically injected with freeze-dried sperm heads, Zygote 13 (2005) $79-85$.

[4] S. Hochi, K. Watanabe, M. Kato, M. Hirabayashi, Live rats resulting from microinjection of oocytes with spermatozoa freeze-dried and stored for one year, Mol. Reprod. Dev. 70 (2008) 1776-1781.

[5] T. Kaneko, N. Nakagata, Improvement in the long-term stability of freeze-dried mouse spermatozoa by adding of a chelating agent, Cryobiology 53 (2006) 279-282.

[6] T. Kaneko, N. Nakagata, Relation between storage temperature and fertilizing ability of freeze-dried mouse spermatozoa, Comp. Med. 55 (2005) 140-144.

[7] T. Kaneko, T. Serikawa, Long-term preservation of freeze-dried mouse spermatozoa, Cryobiology 64 (2012) 211-214.

[8] T. Kaneko, D.G. Whittingham, J.W. Overstreet, R. Yanagimachi, Tolerance of the mouse sperm nuclei to freeze-drying depends on their disulfide status, Biol. Reprod. 69 (2003) 1859-1862.

[9] T. Kaneko, D.G. Whittingham, R. Yanagimachi, Effect of pH value of freeze drying solution on the chromosome integrity and developmental ability of mouse spermatozoa, Biol. Reprod. 68 (2003) 136-139.

[10] T. Kaneko, Sperm freeze-drying and micro-insemination for biobanking and maintenance of genetic diversity in mammals, Reprod. Fertil. Dev. 28 (8) (2016) 1079-1087.

[11] Y. Kawase, H. Suzuki, A study on freeze-drying as a method of preserving mouse sperm, J. Reprod. Dev. 57 (2) (2011) 176-182.

[12] H. Kodama, R. Yamaguchi, J. Fukuda, H. Kasai, T. Tanaka, Increased oxidative deoxyribonucleic acid damage in the spermatozoa of infertile male patients, Fertil. Steril. 68 (1997) 519-524.

[13] H. Kusakabe, M.A. Szczygiel, D.G. Whittingham, R. Yanagimachi, Maintenance of genetic integrity in frozen and freeze-dried mouse spermatozoa, Proc. Natl. Acad. Sci. U. S. A. 98 (2001) 13501-13506.

[14] H. Kusakabe, R. Yanagimachi, Y. Kamiguchi, Mouse and human spermatozoa can be freeze-dried without damaging their chromosomes, Hum. Reprod. 23 (2008) 233-372.

[15] J.L. Liu, H. Kusakabe, C. Chang, H. Suzuk, D.W. Schmidt, M. Julian, R. Pfeffer, C. Bormann, X.C. Tian, R. Yanagimachi, X. Yang, Freeze-dried sperm fertilization leads to full-term development in rabbits, Biol. Reprod. 70 (2004) 1776-1781.

[16] V. Luño, L. Gil, M. Olaciregui, N. González, R.A. Jerez, et al., Rosmarinic acid improves function and in vitro fertilising ability of boar sperm after cryopreservation, Cryobiology 69 (1) (2014) 157-162.

[17] M. Nakai, N. Kashiwazaki, A. Takizawa, N. Maedomari, M. Ozawa, J. Noguchi, H. Kaneko, M. Shino, K. Kikuchi, Effects of chelating agents during freeze-drying of boar spermatozoa on DNA fragmentation and on developmental ability in vitro and in vivo after intracytoplasmic sperm head injection, Zygote 15 (2007) 15-24.

[18] M. Olaciregui, V. Luño, P. Domingo, N. González, L. Gil, In vitro developmental ability of ovine oocytes following intracytoplasmic injection with freeze-dried spermatozoa, Sci. Rep. 7 (1) (2017) 109624.

[19] M. Olaciregui, V. Luño, N. Gonzalez, I. De Blas, L. Gil, Freeze-dried dog sperm: dynamics of DNA integrity, Cryobiology 71 (2) (2015) 286-290.

[20] P. Pereira, D. Tysca, P. Oliveira, L.F. da Silva Brum, J.N. Picada, et al., Neurobehavioral and genotoxic aspects of rosmarinic acid, Pharmacol. Res. 52 (2005) 199-203.

[21] B. Sotolongo, T.T. Huang, E. Isenberger, W.S. Ward, An endogenousnuclease in hamster, mouse, and human spermatozoa cleaves DNA into loop-sized fragments, J. Androl. 26 (2005) 272-280.

[22] G.W. Teebor, R.J. Boorstein, J. Cadet, The repairability of oxidative free radical mediated damage to DNA: a review, Int. J. Radiat. Biol. 54 (2) (1988) 131-150.

[23] J.P. Twigg, D.S. Irvine, R.J. Aitken, Oxidative damage to DNA in human sperma tozoa does not preclude pronucleus formation at intracytoplasmic sperm injection, Hum. Reprod. 13 (7) (1998) 1864-1871.

[24] T. Wakayama, R. Yanagimachi, Development of normal mice from oocytes injected with freeze-dried spermatozoa, Nat. Biotechnol. 16 (1998) 639-641.

[25] M.A. Ward, T. Kaneko, H. Kusakabe, J.D. Biggers, D.G. Whittingham, et al., Longterm preservation of mouse spermatozoa after freeze-drying and freezing without cryoprotection, Biol. Reprod. 69 (6) (2003) 2100-2108.

[26] W. Zhang, K. Yi, C. Chen, X. Hou, X. Zhou, Application of antioxidants and centrifugation for cryopreservation of boar spermatozoa, Anim. Reprod. Sci. 132 (3-4) (2012) 123-128. 